\title{
Erratum to: Determination of heavy metals in fresh water fish species of the River Ravi, Pakistan compared to farmed fish varieties
}

\author{
Shaista Nawaz • Saeed Ahmad Nagra • \\ Yasar Saleem • Amit Priyadarshi
}

Published online: 17 October 2009

C) Springer Science + Business Media B.V. 2009

\section{Erratum to: Environ Monit Assess DOI 10.1007/s10661-009-1064-9}

The original version of this article unfortunately contained a mistake. The name of the last author was incorrect. It should have been "Amit Priyadarshi" instead of "Amit Priydarshi."

The online version of the original article can be found at http://dx.doi.org/10.1007/s10661-009-1064-9.

S. Nawaz $(\varangle)$

Meat Research Laboratory, Food and Biotechnology, Research Centre, PCSIR Labs Complex, Ferozpur

Road, Lahore, Pakistan

e-mail: snpcsir1@hotmail.com

\section{S. A. Nagra}

Institute of Chemistry, University of the Punjab,

Lahore, Pakistan

\section{Y. Saleem}

Centre for Neural Sciences, Korea Institute of Science and Technology (KIST), 39-1 Hawolgok Dong,

Seongbuk Gu, 136-791, Seoul, South Korea
A. Priyadarshi
Biomedical Research Centre, Korea Institute
Y. Saleem · A. Priyadarshi
Department of Biomolecular Science,
University of Science and Technology,
113 Gwahangno, Yuseong-gu, 305-333,
Daejeon, South Korea of Science and Technology (KIST), 39-1 Hawolgok

Dong, Seongbuk Gu, 136-791, Seoul, South Korea 